\title{
Термальная история базального контакта в расслоенном интрузиве Фёдоровой тундры, Кольский регион, Россия
}

\author{
Грошев Н.Ю., Степенщиков Д.Г.
}

Геологический институт КНЦ РАН, Anamumbl,nikolaygroshev@gmail.com

\begin{abstract}
Аннотация. В статье приведены результаты термального моделирования первой интрузивной фазы палеопротерозойского массива Фёдоровой тундры, базальная толща которого вмещает крупное месторождение элементов платиновой группы (ЭПГ). Базальная толща, сложенная такситовыми габброноритами, как считается, образовалась в результате дополнительного внедрения насыщенной сульфидами магмы и представляет собой вторую фазу интрузива. Отсутствие миграции обогащенной ЭПГ сульфидной жидкости из габброноритов в архейские породы фундамента свидетельствует о внедрении второй фазы в значительно остывший контакт первой фазы. Таким образом, минимальное время между этими интрузивными событиями может быть оценено по остыванию нижнего контакта первой фазы до температуры, способствующей возникновению миграции сульфидов $\left(400^{\circ} \mathrm{C}\right)$. Моделирование с учётом среднего геотермического градиента $\left(30^{\circ} \mathrm{C} / \kappa м\right)$ показывает, что это время составляет 600-700 тыс. лет. Полученные результаты подтверждают формирование месторождения Фёдоровой тундры вне стратиграфической последовательности интрузива.

Ключевые слова: Фёдорово-Панский комплекс; месторождение Фёдорова тундра; сульфидное оруденение; элементы платиновой группы; контактовый тип; термальное моделирование.
\end{abstract}

\section{Thermal history of the basal contact in the Fedorova Tundra layered intrusion, Kola Region, Russia}

Groshev N.Yu., Stepenshchikov D.G.

Geological institute KSC RAS, Apatity,nikolaygroshev@gmail.com

\begin{abstract}
The article presents the results of thermal modeling of the first intrusive phase of the Paleoproterozoic Fedorova Tundra massif, whose basal unit hosts a large deposit of platinum group elements (PGE). The basal unit composed of varied-textured gabbronorite is believed to be an additional injection of sulfide-saturated magma or to represent the second phase of the intrusion. The absence of migration of PGE-enriched sulfide liquid from gabbronorites into Archean rocks of the basement is evidence of an injection of the second phase into the significantly cooled basal contact of the first phase. This fact allows us to estimate the minimum time elapsed between these two igneous events. Assuming an average geothermal gradient $\left(30^{\circ} \mathrm{C} / \mathrm{km}\right)$ and a basement temperature of $\sim 400^{\circ} \mathrm{C}$ due to preheating, the modeling shows that this time is 600-700 thousand years. The results confirm that the Fedorova Tundra deposit was formed out-of-sequence in the intrusion.
\end{abstract}

Key words: Fedorova-Pana Complex; Fedorova Tundra deposit; sulfide mineralization; platinum group elements; contact-style; thermal modeling.

\section{Введение}

Критическим фактором формирования контактовых малосульфидных руд элементов платиновой группы (ЭПГ) в расслоенном мафит-ультрамафитовом массиве является предварительный нагрев вмещающих пород за счёт предшествующей формированию интрузива магматической активности (Karykowski et al., 2018). Прогрев рамы до $400^{\circ} \mathrm{C}$ за счёт внедрения, например, серии даек или силлов, предваряющих главную интрузию, создаёт условия для эффективного накопления сульфидных капель вблизи дна магматической камеры, а также для просачивания этих капель в частично расплавленные породы фундамента. На Фенноскандинавском щите примерами интрузий, где этот фактор играл решающую роль, являются расслоенные комплексы Портимо и Мончегорский (Iljina, 1994; Karykowski et al., 2018).

По существующим представлениям первая интрузивная фаза массива Фёдоровой тундры (центральная часть Кольского полуострова) выступает в качестве возможного источника предварительного нагрева для на порядок меньшей по объёму базальной толщи (рис. 1, a) или второй интрузивной фазы, содержащей контактовое ЭПГ-оруденение (Schissel et al., 2002; Groshev et al., 2009). 
(a)

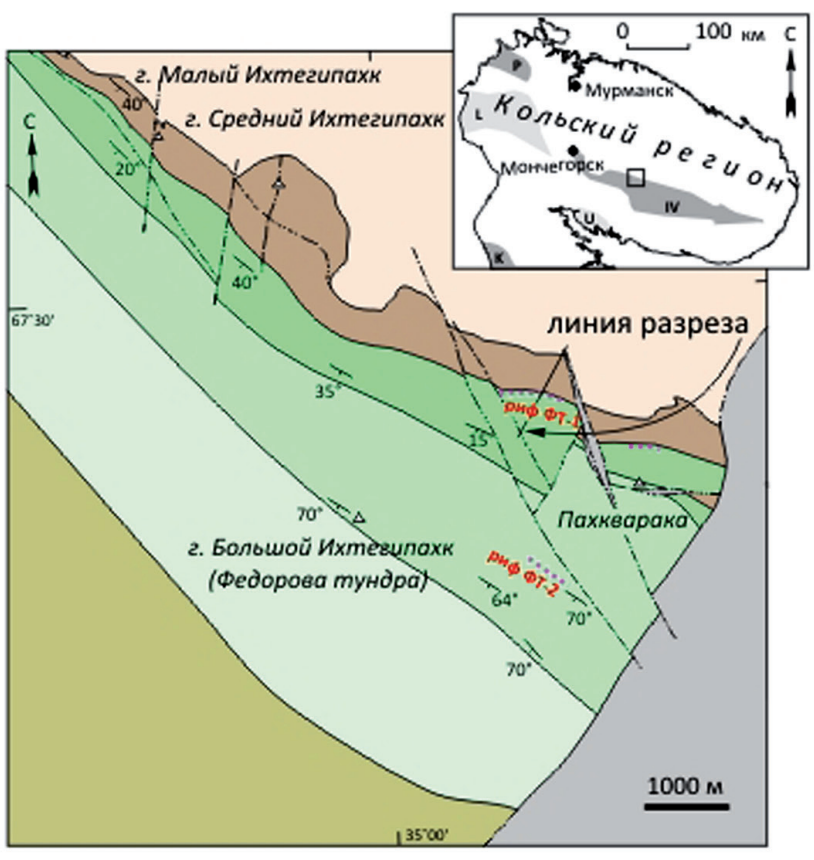

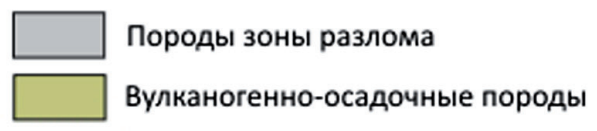

Вторая интрузивная фаза

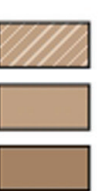

Метагаббронорит мелкозернистый

Габбронорит такситовый

Меланорит такситовый

Первая интрузивная фаза

Лейкогаббро

Переслаивание лейкогаббро

и лейкогабброноритов

Лейкогаббро с прослоями

мезогабброноритов

Троктолит

Ортопироксенит

Гнейсы и диориты

архейского фундамента

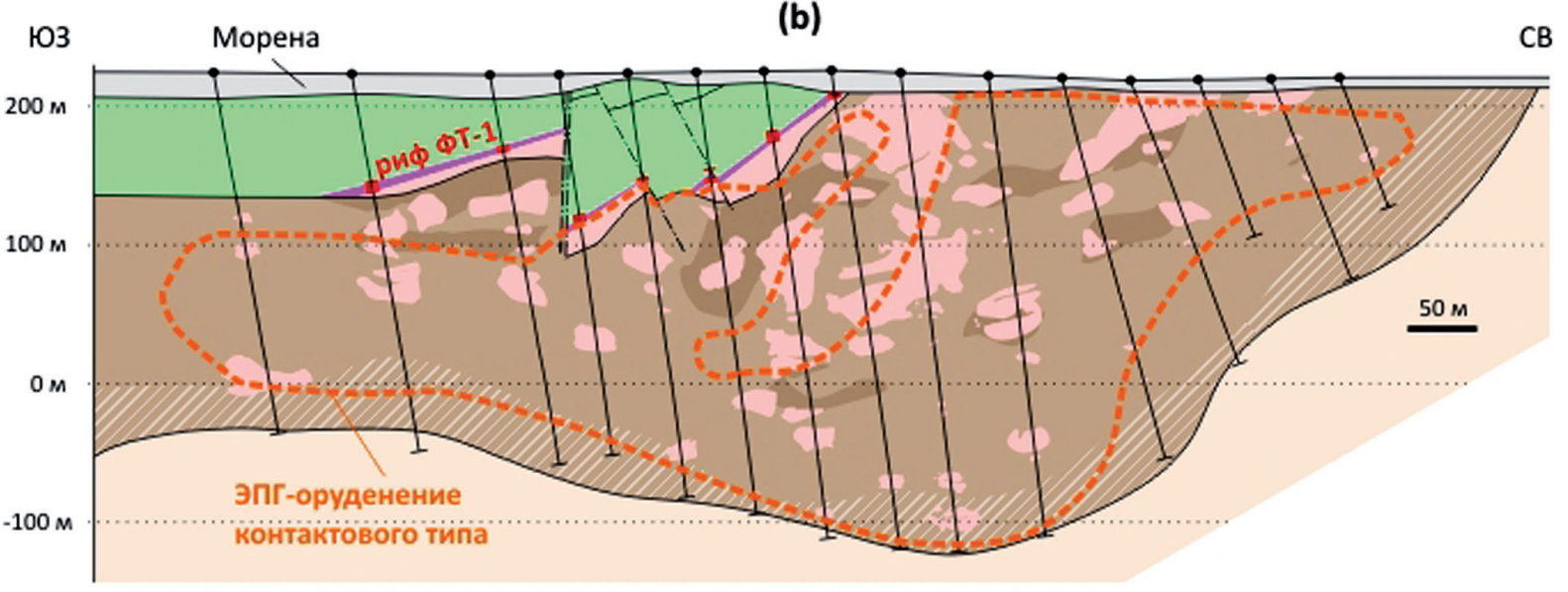

Рис. 1. Упрощённая геологическая карта интрузива Фёдоровой тундры (a) и схематичный геологический разрез месторождения (b). Фиолетовые пунктирные линии обозначают положение платинометалльных рифов ФТ-1 и ФТ-2 на карте; красные прямоугольники указывают на минерализованные интервалы рифа ФТ-1 в скважинах. Протерозойские структуры преимущественно архейского Кольского региона (врезка): палеорифты Имандра-Варзуга (IV), Куолаярви (K) и Печенга (P); гранулитовые пояса Лапландский (L) и Умбинский (U). С изменениями по (Грошев, Савченко, 2011).

Fig. 1. Simplified geologic map of the Fedorova Tundra intrusion (a) and schematic geologic cross section through the deposit (b). Purple dotted lines show a position of PGE reefs (FT-1 and FT-2) on the map; red rectangles on the cross section indicate mineralized intervals of the FT-1 Reef. Proterozoic structures of the predominantly Archean Kola Region (inset): Imandra-Varzuga (IV), Kuolajarvi (K), and Pechenga (P) paleorift structures; Lapland (L) and Umba (U) granulite belts. Modified after (Groshev, Savchenko, 2011).

В случае значительного теплового влияния первой фазы в строении рудной зоны должны быть проявлены процессы миграции сульфидной жидкости, однако признаков этих процессов в рудоносной толще не наблюдается. Такситовые габбронориты базальной толщи на всей её мощности до 300 м содержат неравномерную вкрапленность сульфидов (2-5 об. \%). Равномерно-вкрапленные сульфиды (20-30 об. \%) встречаются незакономерно и крайне редко, массивные сульфидные руды практически отсутствуют; оруденение полностью локализовано в пределах интрузии - просачивания суль- 
фидной жидкости в породы фундамента не отмечается (рис. 1, b). Следовательно, внедрение второй интрузивной фазы произошло, по-видимому, после значительного остывания пород первой фазы массива. Целью настоящего исследования является оценка временного разрыва между интрузивными фазами массива Фёдоровой тундры с помощью математического моделирования и обсуждение результатов в контексте длительности кристаллизации расслоенных интрузий и формирования ЭПГ-оруденения контактового типа.

\section{Результаты термального моделирования}

Остывание первой интрузивной фазы массива Фёдоровой тундры может быть промоделировано теплообменом пластовой магматической толщи с температурой $1200^{\circ} \mathrm{C}$, внедрившейся в архейский фундамент на глубине 5 км (Дубровский, Рундквист, 2008). Мощность пластового тела составляет 4 км (Грошев, 2011). Дискретизация одномерного уравнения теплопроводности даёт рекуррентную формулу:

$$
T_{i}^{n+1}=T_{i}^{n}+k \Delta t\left(\frac{T_{i+1}^{n}-2 T_{i}^{n}+T_{i-1}^{n}}{(\Delta x)^{2}}\right),
$$

где $k$ обозначает температуропроводность $\left(k=2 \times 10^{-6} \mathrm{M}^{2} \mathrm{c}^{-1}\right)$, а $T_{i}^{n}-$ температуру на глубине $i \times \Delta x \mathrm{M}$ через $n \times \Delta t$ лет. Подробный вывод уравнения приведён в (Karykowski et al., 2018). Для устранения граничных эффектов глубина моделирования была увеличена до 20 км.

Таблица 1. Результаты термального моделирования первой интрузивной фазы массива Фёдоровой тундры.

Table 1. Thermal modeling results for the first intrusive phase of the Fedorova Tundra massif.

\begin{tabular}{lcc}
\hline $\begin{array}{c}\text { Время после } \\
\text { внедрения, } \mathrm{t} \text { (лет) }\end{array}$ & \multicolumn{2}{c}{ Температура, $\mathrm{T}\left({ }^{\circ} \mathrm{C}\right)$} \\
\hline на глубине 5 км & на глубине 9 км \\
\hline 1 & 839 & 880 \\
10 & 732 & 787 \\
100 & 692 & 753 \\
1000 & 677 & 744 \\
10000 & 663 & 750 \\
100000 & 517 & 635 \\
200000 & 415 & 551 \\
300000 & 350 & 500 \\
400000 & 306 & 462 \\
500000 & 276 & 431 \\
600000 & 254 & 407 \\
700000 & 236 & 386 \\
800000 & 223 & 369 \\
900000 & 211 & 355 \\
1000000 & 202 & 342
\end{tabular}

Моделирование показывает (рис. 2, а; табл. 1), что внедрение первой интрузивной фазы приведёт к значительному прогреву подстилающих пород, которые через 25 тыс. лет будут на 250 м вниз от базального контакта прогреты выше температуры частичного плавления фундамента $\left(700^{\circ} \mathrm{C}\right)$. В случае, если первая интрузивная фаза содержала бы кумулусные сульфиды, они должны были бы осаждаться вблизи дна камеры, формируя в различной степени обогащенные прослои, и просачиваться в архейские диориты и гнейсы. Поскольку миграции сульфидной жидкости не наблюдается (рис. 1, b), магма первой фазы при внедрении, по-видимому, не была в целом насыщена сульфида- 


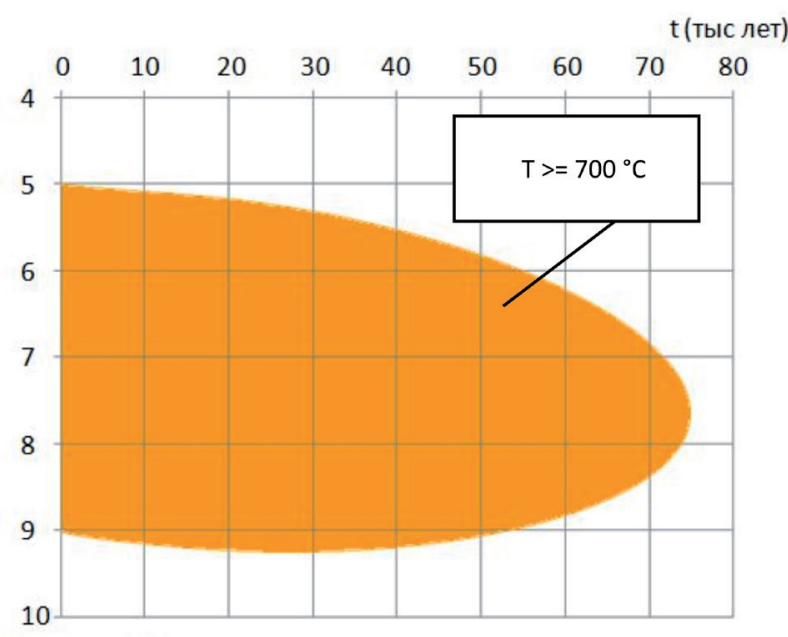

Глубина (км)

(a)

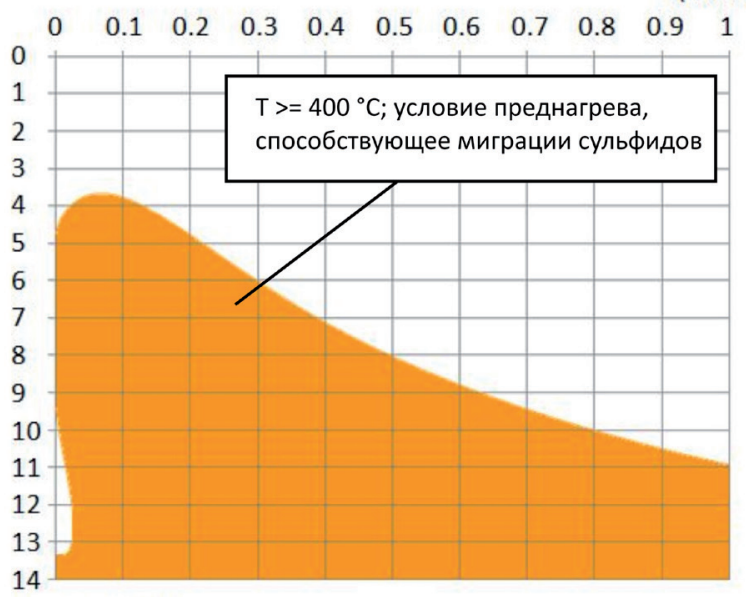

(b)

Рис. 2. Графики время-глубина, показывающие температурные области свыше $700^{\circ} \mathrm{C}$ (a) и свыше $400^{\circ} \mathrm{C}$ (b) после внедрения первой интрузивной фазы массива Фёдоровой тундры.

Fig. 2. Time-depth graphs showing temperature intervals over $700^{\circ} \mathrm{C}$ (a) and over $400^{\circ} \mathrm{C}(\mathrm{b})$ after the intrusion of the first phase of the Fedorova Tundra massif.

ми. В свою очередь, базальная толща такситовых габброноритов, очевидно, принадлежит к последующему магматическому эпизоду, произошедшему после снижения температуры в нижнем контакте первой фазы до $400^{\circ} \mathrm{C}$. Как видно из рисунка 2 , b и таблицы 1 , минимальное время, разделяющее интрузивные фазы, при данных граничных условиях составляет 600-700 тыс. лет.

\section{Обсуждение результатов}

Термальное моделирование на примере массива Федоровой тундры показывает, что длительность кристаллизации мафит-ультрамафитового интрузива в условиях открытой системы составляет как минимум сотни тысяч лет (рис. 2, b). Вместе с тем, последние данные систематического изотопного датирования расслоенных интрузий, образованных в открытых системах, показывают, что длительность их кристаллизации составляет 1-3 млн. лет при ошибке отдельных определений возраста до 0.26 млн. лет по модулю (Zeh et al., 2015; Scoates, Wall, 2015; Wall et al., 2018). Стоит отметить, что существующая изотопно-геохронологическая оценка длительности кристаллизации массива Федоровой тундры в 40 млн. лет (Groshev et al., 2009), очевидно, является сильно завышенной из-за вероятного включения вторичного циркона в расчет U-Pb возраста (Groshev, Karykowski, 2018). Таким образом, уточнение возраста интрузивных фаз этого массива является одной из наиболее интересных нерешенных задач в петрологии расслоенных массивов Фенноскандинавского щита.

Наличие или отсутствие миграции сульфидной жидкости из базальных рудных зон в породы фундамента является важным генетическим признаком для контактовых месторождений ЭПГ, раскрывающим их термальную историю. Кроме массива Федоровой тундры, это может быть продемонстрировано с помощью термального моделирования массива Нюд-Поаз (Мончегорский комплекс), имеющего две рудоносные интрузивные фазы, каждая из которых содержит вкрапленные сульфиды, мигрирующие за пределы интрузии в фундамент (Karykowski et al., 2018; Грошев, Припачкин, 2018). Вторая интрузивная фаза (массив Габбро-10), расположенная вдоль базального контакта массива Нюд-Поаз, содержит ЭПГ-оруденение, которое просачивается в архейский фундамент на расстояние до 30 м. Следовательно, дополнительная инъекция насыщенной сульфидами магмы произошла во время, когда базальный контакт массива Нюд-Поаз (первой фазы) все еще имел высокую температуру. Временной разрыв между этими фазами, согласно термальному моделированию, составляет не более 150 тысяч лет. Точность изотопного датирования в настоящий момент не позволяет установить такое небольшое временное различие (Scoates, Wall, 2015). Это так- 
же видно по результатам изотопного датирования массива Габбро-10, возраст которого совпадает с возрастом массива Нюд-Поаз в пределах погрешности (Groshev et al., 2018).

Работа выполнена в рамках темы НИР №0226-2019-0053.

\section{Литература}

1. Грошев Н.Ю., Савченко Е.Э. Риф Невидимый - новый уровень малосульфидной платинометальной минерализации в массиве Фёдоровой тундры (Кольский полуостров, Россия) // Руды и металлы. 2011. № 5. C. 15-26.

2. Грошев Н.Ю. Федоровотундровский массив Федорово-Панского платиноносного расслоенного комплекса (Кольский полуостров) - новые петрохимические и геохимические данные // Вестник КНЦ. 2011. № 1. С. 17-29.

3. Грошев Н.Ю., Припачкин П.В. К вопросу о геологической позиции и платиноносности массива Габбро-10, Мончегорский комплекс, Кольский регион // Руды и металлы. 2018. № 4. С. 4-13.

4. Дубровский М.И., Рундквист Т.В. Петрология раннепротерозойского платиноносного массива Фёдоровых тундр (Кольский полуостров) // Записки Российского минералогического общества. 2008. Т. 137. № 4. С. 20-33.

5. Groshev N.Y., Nitkina E.A., Mitrofanov F.P. Two-phase mechanism of the formation of platinum-metal basites of the Fedorova Tundra intrusion on the Kola Peninsula: New data on geology and isotope geochronology // Doklady Earth Sciences. 2009. V. 427. № 2. P. 1012-1016.

6. Groshev N.Yu., Pripachkin P.V., Karykowski B.T., Malygina A.V., Rodionov N.V. and Belyatsky B.V. Genesis of a Magnetite Layer in the Gabbro-10 Intrusion, Monchegorsk Complex, Kola Region: U-Pb SHRIMP-II Dating of Metadiorites // Geology of Ore Deposits. 2018. V. 60. N. 6. P. 486-496.

7. Groshev N. Y., Karykowski B. T. The Main Anorthosite Layer of the West-Pana Intrusion, Kola Region: Geology and U-Pb Age Dating // Minerals. 2019. V. 9. №. 2. P. 71.

8. Iljina M. The Portimo layered igneous complex: with emphasis on diverse sulphide and platinum-group element deposits. Ouluensis Universitas, 1994.

9. Karykowski B.T., Maier W.D., Groshev N. Y., Barnes S. J., Pripachkin P. V., McDonald I., Savard D. Critical Controls on the Formation of Contact-Style PGE-Ni-Cu Mineralization: Evidence from the Paleoproterozoic Monchegorsk Complex, Kola Region, Russia// Economic Geology. 2018. 113(4). P. 911-935. DOI: 10.5382/econgeo.2018.4576

10. Schissel D., Tsvetkov A.A., Mitrofanov F.P., Korchagin A.U. Basal platinum-group element mineralization in the Federov Pansky layered mafic intrusion, Kola Peninsula, Russia. Economic geology. 2002. 97(8). P. 1657-1677.

11. Scoates J.S., Wall C.J. Geochronology of layered intrusions / Layered intrusions. Springer, Dordrecht, 2015. P. 3-74.

12. Wall C. J., Scoates J. S., Weis D., Friedman R. M., Amini M., Meurer W. P. The Stillwater Complex: integrating zircon geochronological and geochemical constraints on the age, emplacement history and crystallization of a large, open-system layered intrusion // Journal of Petrology. 2018. 59(1). P. 153-190.

13. Zeh A., Ovtcharova M., Wilson A. H., Schaltegger U. The Bushveld Complex was emplaced and cooled in less than one million years-results of zirconology, and geotectonic implications // Earth and Planetary Science Letters. 2015. 418. P. 103-114. 